Volume. 4 Nomor. 1

Periode: Januari - Juni 2020; hal. 28-33

p-ISSN : 2580-1112; e-ISSN : 2655-6669

Copyrighr @2020

Penulis memiliki hak cipta atas artikel ini journal homepage: https://ejournal.akperfatmawati.ac.id

DOI:10.46749/jiko.v3i2.37
Jurnal Ilmiah Keperawatan Orthopedi

(JIKO)

Article history:

Received: Desember 12, 19

Revised: September 06, 20

Accepted: September 09, 20

\title{
Efektivitas Virtual Reality Terhadap Prosedur Venapunksi Pada Pasien Anak
}

\author{
Indah Reski Amallia ${ }^{1}$, La Ode Abd Rahman ${ }^{2}$ \\ ${ }^{1}$ Rumah Sakit Universitas Hasanuddin \\ ${ }^{2}$ Departemen Dasar Keperawatan dan Keperawatan Dasar Fakultas Ilmu Keperawatan \\ Universitas Indonesia
}

\begin{abstract}
Abstrak
Anak-anak yang dirawat di rumah sakit mengalami rasa sakit dan kecemasan dari prosedur invasif dan atau penyakit yang mendasarinya. Venapunksi merupakan prosedur terkait jarum yang sering menjadi pengalaman menakutkan bagi pasien anak. Tinjaun ini bertujuan untuk mengetahui efektifitas $V R$ dalam prosedur venapunksi pada pasien anak. metode kualitatif dilakukan di ClinicalKey, Springer, dan Oxford. Penelitian tersebut adalah artikel asli, ulasan sejawat dari tahun 2017 hingga 2019, yang berfokus pada efektifitas VR terhadap prosedur venapunksi untuk menurunkan nyeri pada anak. Hasil penelitian menunjukkan bahwa $V R$ dapat memberikan implikasi praktis yang signifikan dalam mengatasi rasa sakit, kecemasan, dan stres pada pasien anak. Kesimpulan penelitian ini adalah $V R$ merupakan strategi non farmakologi yang dapat meningkatkan rasa nyaman dan kepatuhan dalam prosedur venapunksi pada pasien anak.
\end{abstract}

Kata Kunci: Virtual Reality, Venapunksi, Keperawatan Anak

\begin{abstract}
Children who are hospitalized experience pain and anxiety from invasive procedures and or underlying diseases. Venapunksi is a needle-related procedure that is often a frightening experience for pediatric patients. This review aims to determine the effectiveness of VR in venapunksi procedures in pediatric patients. Qualitative methods are carried out at ClinicalKey, Springer, and Oxford. The study was an original article, peer review from 2017 to 2019, which focused on the effectiveness of VR on venapunksi procedures to reduce pain in children. The results show that VR can have significant practical implications in overcoming pain, anxiety, and stress in pediatric patients. The conclusion of this study is that VR is a non-pharmacological strategy that can increase the sense of comfort and adherence in venapunksi procedures in pediatric patients.
\end{abstract}

Keywords: Virtual Reality, Venipuncture, Pediatric Nursing,

1,2 e-mail: bojandah@gmail.com 


\section{Pendahuluan}

Anak-anak yang dirawat di rumah sakit mengalami rasa sakit dan kecemasan dari prosedur invasif dan atau penyakit yang mendasarinya (Atrozi et al., 2018; Yuan et al., 2017; Aydin \& Ozyazicioglu, 2019).

Venapunksi, prosedur terkait jarum yang sering dilakukan, adalah salah satu pengalaman yang paling menakutkan dan sumber umum dari nyeri sedang hingga berat untuk pasien anak- anak. Rasa sakit yang terkait dengan prosedur ini hanya sekunder setelah penyakit itu sendiri (Wong, Lui, \& Choi, 2019).

Manajemen nyeri yang tidak memadai dapat berdampak negatif pada anak-anak, orang tua, dan institusi medis. Nyeri prosedural terkait jarum yang tidak dikelola pada anak-anak dikaitkan dengan peningkatan nyeri dan stres selama prosedur selanjutnya, ketakutan dan penghindaran perawatan medis, atau bahkan ketidaksukaan terhadap jarum yang bertahan hingga dewasa.

Kegagalan untuk mengelola rasa sakit yang berhubungan dengan jarum dapat meningkatkan tenaga kerja, sumber daya, dan waktu yang dibutuhkan untuk menyelesaikan prosedur, akibatnya mengurangi kepuasan penyedia layanan kesehatan sehubungan dengan prosedur (Wong, Lui, \& Choi, 2019).

Virtual reality (VR) adalah teknologi komputer yang menciptakan lingkungan simulasi 3 dimensi buatan. Realitas virtual terdiri dari tampilan yang dipasang di kepala dan sepasang kacamata tebal yang terhubung ke komputer atau ponsel.

Headset ini memiliki sensor yang melacak gerakan kepala pengguna, menciptakan ilusi bergerak di ruang virtual. Meskipun awalnya dirancang untuk tujuan hiburan, potensi penggunaan VR di bidang medis baru-baru ini dieksplorasi (Arene, Behboudi, \& Goldman 2017).

Mekanisme bagaimana VR mengurangi rasa sakit masih dalam penyelidikan, menurut Hoff man dkk dalam Atzori et al. (2018), yang menerapkan Attention Pain Theory bahwa diperlukan perhatian untuk merasakan sakit, tetapi berada di lingkungan virtual adalah ilusi dan interaksi pasien dengan benda-benda di dunia maya mengurangi jumlah sumber daya perhatian yang telah tersedia di otak pasien untuk menangani rangsangan yang menyakitkan, sehingga mengurangi rasa sakit yang disadari.

Sebuah literature review tentang dampak penggunaan VR untuk mengurangi rasa nyeri pada tindakan venapunksi yang menganalisa 10 (sepuluh) penelitian yang menunjukkan hubungan antara keduanya.

Ini menjadi perhatian karena mampu mengurangi kecemasan anak dalam tindakan venapunksi sehingga mengurangi trauma berkepanjangan yang dapat menghambat proses penyembuhan. VR merupakan perkembangan teknologi yang dapat diaplikasikan di multidisiplin kesehatan.

\section{Metode}

Tinjauan literature review dari studi primer menggunakan metode kualitatif dilakukan di ClinicalKey, Springer, dan Oxford. Penelitian tersebut adalah artikel asli, ulasan sejawat dari tahun 2017 hingga 2019, yang berfokus pada efektifitas VR terhadap prosedur venapunksi untuk menurunkan nyeri pada anak.

Langkah pertama yang dilakukan adalah merumuskan pertanyaan : "dalam konteks literatur ilmiah di seluruh dunia, bagaimana VR telah digunakan dan apa dampaknya pada prosedur venapunksi pada pasien anak?"

Lokasi artikel diperoleh dari 10 (sepuluh) database yang menggunakan The Journal of Pediatric, Journal of PeriAnesthesia Nursing, Child Health Update, Frontiers in Psychology, Oxford Journal, dan Springer.

Seleksi pencarian terdiri dari kombinasi kata kunci yang berbeda yang 
mencakup objek utama yang sedang ditinjau (misal virtual reality, 3D, technologi) yang dipertimbangkan dengan subjek (hospitalisasi, nyeri venapunksi, dan keperawatan pediatrik).

Sebagai langkah untuk evaluasi kritis penelitian, judul dan abstrak dianalisis, menganalisisnya sesuai dengan pertanyaan pedoman dan kriteria inklusi dan kriteria eksklusi. Setelah itu, artikelartikel disusun menjadi instrumen yang berisi informasi yang diperlukan untuk menjawab pertanyaan penelitian.

Evaluasi kritis penelitian termasuk membaca dan menganalisis isi. Sehingga informasi yang dianggap penting/relevan dikumpulkan untuk mencapai tujuan penelitian, seperti jenis studi, variabel yang dianalisis, objektivitas dan temuan utama. Akhirnya, tahap terakhir dari peninjauan dicapai melalui sintesis konten untuk mengatur presentasi dan interpretasi data.

\section{Pembahasan}

Venapunksi adalah prosedur needle related paling menyakitkan dan menyedihkan yang dialami oleh pasien anak. Namun, nyeri prosedural masih kurang terdiagnosis dan diobati pada kelompok rentan ini.

Mengingat konsekuensi negatif dari nyeri prosedural yang tidak terkelola kepada pasien, orang tua, dan institusi medis, diperlukan intervensi yang efektif untuk meminimalkan rasa sakit dan kesulitan yang dialami oleh pasien anak yang menjalani venapunksi.

Memberikan intervensi yang mengintegrasikan gangguan dengan informasi prosedural sesuai usia dapat secara efektif mengurangi rasa sakit dan kecemasan di antara pasien anak yang menjalani venapunksi (Wong, Lui, \& Choi, 2019).
Gambar 1. Penggunaan VR pada prosedur venapunksi

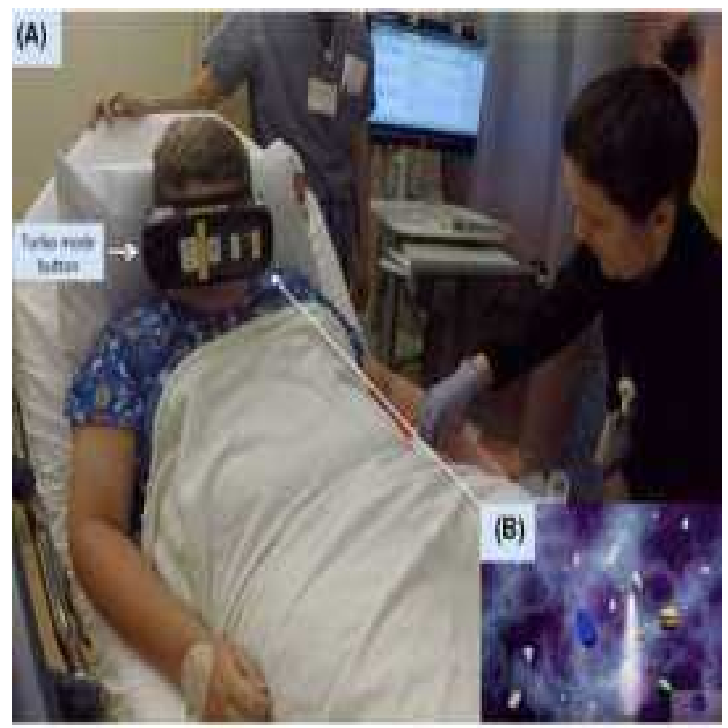

Sumber: Yuan et al., (2017) Canadian Journal of Anesthesia

Nyeri adalah pengalaman kompleks yang terdiri dari komponen sensorik, kognitif, perilaku, dan psikologis. Prosedur yang menyakitkan, seperti vaksinasi, suntikan intravena, perbaikan laserasi, dan ganti balutan untuk luka bakar adalah bagian umum dari perawatan medis anak.

Situasi yang menyakitkan selama prosedur ini sering menimbulkan kecemasan bagi pasien, yang dapat menyebabkan ketakutan dan sangat memengaruhi kepatuhan terhadap perawatan untuk prosedur di masa mendatang.

Lebih jauh, kondisi yang menyebabkan nyeri kronis, seperti penyakit sel sabit, mungkin juga memiliki efek merugikan pada kehidupan anakanak. Analgesia farmakologis pediatrik yang umum termasuk terapi opioid, yang dikenal memiliki toleransi dan ketergantungan yang tinggi dengan efek samping mulai dari mual dan sembelit hingga gangguan kognitif dan depresi pernapasan.

Teknik yang digunakan oleh para profesional perawatan kesehatan untuk mengelola dan menurunkan kecemasan, 
dan mungkin rasa sakit, selama prosedur yang menyakitkan pada pasien anak-anak.

Distraksi pasif (misalnya menonton televisi, mendengarkan buku) dan distraksi aktif (misalnya, mainan interaktif, permainan elektronik) telah dipelajari secara luas dan menyebabkan penurunan rasa sakit dan kecemasan. Virtual reality mungkin menawarkan lebih banyak distraksi, karena benar-benar membenamkan pasien di dunia lain dan melibatkan banyak indera. Pasien dapat berpartisipasi aktif atau pasif dalam berbagai program potensial (Arene, Behboudi, \& Goldman, 2017).

Secara umum, nyeri terdiri dari tiga dimensi: sensori-diskriminatif, afektif- motivasi, dan kognitif-evaluatif. Dimensi sensori-diskriminatif mengacu pada mekanisme nosiseptif, seperti lokasi, durasi, dan luasnya rasa sakit.

Dimensi afektif-motivasi adalah sensasi yang tidak menyenangkan yang disebabkan oleh rasa sakit, dihubungkan langsung dengan keadaan psikis dan konteks budaya orang tersebut dan dimensi kognitif-evaluatif terdiri dari serangkaian proses modulasi nyeri, seperti fenomena gangguan- perhatian, yang meliputi makna dan interpretasi orang tersebut sehubungan dengan momen menyakitkan (Scapin et al., 2018).

Berdasarkan model Interrupt of Attention and Pain dari Eccleston dan Crombez (1999), rasa sakit memerlukan perhatian, dan manusia memiliki sumber daya perhatian yang terbatas, kami memperkirakan bahwa pasien akan memusatkan perhatian mereka pada VR, dan akan memiliki lebih sedikit sumber daya perhatian yang tersedia untuk fokus pada rasa sakit.

Seperti yang diperkirakan, anakanak dan pasien remaja melaporkan pengurangan yang signifikan dalam ketidaknyamanan rasa sakit, melaporkan menghabiskan waktu yang jauh lebih sedikit untuk memikirkan rasa sakit mereka selama venapunksi dan melaporkan intensitas nyeri yang lebih rendah secara signifikan selama VR. Seperti yang diperkirakan, pasien anakanak dan remaja melaporkan kesenangan yang jauh lebih besar ketika mereka menggunakan VR selama venapunksi mereka (Atzori et al., 2018).

Teori di balik peran VR dalam mengurangi rasa sakit dan tidak hanya kecemasan terkait dengan kapasitas atensi terbatas yang dimiliki manusia. Nyeri membutuhkan perhatian, dan jika sebagian perhatian itu dapat dialihkan (misalnya, dengan berinteraksi dengan VR), pasien akan memiliki respons yang lebih lambat terhadap sinyal nyeri yang masuk. Nyeri dideteksi oleh nosiseptor yang terletak di seluruh tubuh yang menyampaikan sinyal nyeri ke sistem saraf pusat melalui serat-serat.

Banyak analgesik bekerja dengan mengganggu jalur serat-C, sehingga mengganggu cara manusia merasakan sakit. VR tidak mengganggu sinyal rasa sakit tetapi bertindak baik secara langsung maupun tidak langsung pada persepsi nyeri dan pensinyalan melalui perhatian, emosi, konsentrasi, memori, dan indera lain.

Sebuah penelitian yang menggunakan pencitraan resonansi magnetik fungsional pasien sehat yang menggunakan VR sambil terpapar dengan stimulus menyakitkan (stimulator nyeri termal pada kaki) menunjukkan pengurangan lebih besar dari $50 \%$ dalam aktivitas otak yang berhubungan dengan nyeri di 5 area otak (Arene, Behboudi, \& Goldman (2017).

Mengurangi kecemasan sangat penting karena ketika kecemasan diminimalkan anak-anak akan patuh terhadap prosedur, dengan melakukan peningkatan kenyamanan dan kontrol. Mengurangi rasa sakit dan kecemasan adalah penting pada anak karena kecemasan disebabkan oleh nyeri prosedural dapat meningkatkan stres pasien, dan ketika pasien stres, proses penyembuhan dapat terganggu, misalnya, stres yang berhubungan dengan proses 
penyembuhan, dapat lebih lambat pada pasien yang menjalani berbagai jenis perawatan luka (Burns-Nader \& Pinion K., 2017).

\section{Kesimpulan}

VR diaplikasikan menggunakan fitur tiga dimensi dan video game. Temuan menunjukkan hubungan teknologi ini dengan peningkatan kenyamanan dan pengurangan rasa sakit, kecemasan dan stres pasien selama menjalani prosedur venapunksi. Dampak utama dari intervensi ini adalah untuk meningkatkan kepatuhan prosedural, akibatnya mengurangi panjang dan biaya prosedur sehingga meningkatkan kepuasan penyedia layanan kesehatan.

VR adalah strategi non farmokologi yang telah terbukti bermanfaat dalam pengobatan dan perawatan pasien anak. VR dapat dianggap sebagai teknik pengalih perhatian yang efektif untuk manajemen nyeri anak-anak dan remaja selama venapunksi. Selain itu, VR dapat menimbulkan emosi positif, lebih dari pada teknik distraksi tradisional.

VR layak, dapat ditoleransi, dan disukai oleh pasien, perawat, dan phlebotomists untuk pengambilan darah rutin. VR dapat dijadikan intervensi preventif yang mengubah pengalaman pengambilan darah atau venapunksi yang menjadi prosedur medis rutin yang kurang menyakitkan dan berpotensi tanpa rasa sakit, terutama untuk pasien anak-anak dengan sensitivitas kecemasan yang tinggi.

\section{Terima Kasih}

Ucapan terima kasih yang sebesarbesarnya kepada Magister Ilmu Keperawatan Anak Fakultas Ilmu Keperawatan Universitas Indonesia atas kesempatan yang telah diberikan dalam pembuatan literature review ini.

\section{Daftar Pustaka}

Arane, K., Behboudi, A., \& Goldman, R.
D. (2017). Virtual reality for pain and anxiety management in children. Canadian Family Physician, 63(12), 932-938.

Atzori, B., Hoffman, H. G., Vagnoli, L., Patterson, D. R., Alhalabi, W., Messeri, A., \& Grotto, R. L. (2018). Virtual reality analgesia during venipuncture in pediatric patients with onco-hematological diseases. Frontiers in Psychology, 9(DEC), 1-7.

https://doi.org/10.3389/fpsyg.201 $\underline{8.02508}$

Aydın, A. ., \& Özyazıcıŏ̆lu, N. (2019). Using a Virtual Reality Headset to Decrease Pain Felt During a Venipuncture Procedure in Children. Journal of PeriAnesthesia Nursing, 1-7. https://doi.org/10.1016/j.jopan.20 19.05 .134

Barone, et al. (2018). Virtual Reality as a Distraction Intervention to Relieve Pain and Distress during Medical Procedures. Clinical Journal of Pain. Lippincott Williams and Wilkins.

https://doi.org/10.1097/AJP.00000 00000000599.

Burns-Nader, S., Joe, L., \& Pinion, K. (2017). Computer tablet distraction reduces pain and anxiety in pediatric burn patients undergoing hydrotherapy: A randomized trial. Burns, 43(6), 1203-1211.

https://doi.org/10.1016/j.burns.20 $\underline{17.02 .015}$

Chan, E., Hovenden, M., Ramage, E., Ling, N., Pham, J. H., Rahim, A., ... Leong, P. (2019). Virtual Reality for Pediatric Needle Procedural Pain: Two

Randomized Clinical Trials. Journal of Pediatrics, 209, 160167.e4.

https://doi.org/10.1016/j.jpeds.201 9.02.034

Diaz-Hennessey, S., O'Shea, E. R., \& 
King, K. (2019). Virtual reality: Augmenting the acute pain experience in children. Pediatric Nursing, 45(3), 122-127. Retrieved from https://search.proquest.com/openvie w/273b8310b36e6982b6fbd58269 11 ae $59 / 1$ ?pqorigsite $=$ gscholar $\& \mathrm{cbl}=47659$

Gerceker et al. (2018). Effects of Virtual Reality and External Cold and Vibration on Pain in 7- to 12Year-Old Children During Phlebotomy: A Randomized Controlled Trial. American Society of PeriAnesthesia Nurses. https://www.jopan.org/article/S10 89-9472(18)30011-X/fulltext

Gold, J. I., \& Mahrer, N. E. (2018). Is virtual reality ready for prime time in the medical space? A randomized control trial of pediatric virtual reality for acute procedural pain management. Journal of Pediatric Psychology, 43(3), 266-275. https://doi.org/10.1093/jpepsy/jsx 129

Scapin, S., Echevarría-Guanilo, M. E., Boeira Fuculo Junior, P. R., Gonçalves, N., Rocha, P. K., \& Coimbra, R. (2018). Virtual Reality in the treatment of burn patients: A systematic review. Burns, 44(6), 1403-1416. https://doi.org/10.1016/j.burns.201 7.11 .002

Shetty, Suresh, \& Hegde. (2019) . Effect of Virtual Reality Distraction on Pain and Anxiety During Dental Treatment in 5 to 8 Year Old Children. Journal of Clinical Pediatric Dentistry Vol. 43, No. 2, pp.

97-102.

https://jocpd.org/doi/10.17796/105 3-4625-43.2.5

Yuan, J. C., Rodriguez, S., Caruso, T. J., \& Tsui, J. H. (2017). Providercontrolled virtual reality experience may adjust for cognitive load during vascular access in pediatric patients. Canadian Journal of Anesthesia, 64(12), 1275-1276. https://doi.org/10.1007/s12630017-0962-5

Wong, C. L., Lui, M. M. W., \& Choi, K. C. (2019). Effects of immersive virtual reality intervention on pain and anxiety among pediatric patients undergoing venipuncture: A study protocol for a randomized controlled trial. Trials, 20(1), 110.

https://doi.org/10.1186/s13063$\underline{019-3443-\mathrm{Z}}$ 